\title{
Financial reporting: profitability ratios in the different stages of life cycle
}

\author{
Erkki K. Laitinen \\ Professor Emeritus of Accounting and Business Finance \\ Department of Accounting and Business Finance \\ University of Vaasa, Finland
}

Teija Laitinen

Professor of Accounting and Business Finance

Department of Accounting and Business Finance

University of Vaasa, Finland

\begin{abstract}
This study develops a mathematical framework to analyze the time-series of profitability ratios across different stages of life cycle. This study extends the analysis of ratios in the early stages of a startup outlined by Laitinen (2017) to contribute to the life cycle research. The growth of expenditure is assumed to consist of the difference of two steady growth processes: stand-alone growth and growth of competition impact. If the growth rate of competition impact exceeds the stand-alone growth rate, an $S$ shaped curve as a life cycle is resulted. Each periodic expenditure is assumed to generate a proportionally identical flow of revenue with a constant internal rate of return (IRR) and distributed geometric lag structure. The firm is expensing in each period a fixed part of periodic expenditure and beginning-of-the-period assets. It is shown that the time-series of profitability ratios are sensitive especially to the rate of expense emphasizing the role of expense method in financial reporting. If the rate of expense is not consistent with the revenue lag, profitability ratios show strong divergent variation (spread) across the early years (birth stage) and during the decline stage. Thus, in particular in these stages, profitability ratios are unable to reflect IRR properly.
\end{abstract}

Key words: time series; profitability ratios; life cycle; distributed lag model; IRR; growth JEL classifications: $M$ Business Administration and Business Economics Marketing; Accounting, M4 Accounting, M41 Accounting

\section{INTRODUCTION}

For several hundred years, scientists using statistical analysis have observed the regulation of system evolution as an initial slow change followed by a rapid change and finally ending in a slow change again (Kucharavy \& De Guio, 2015). Thus, systems in general tend to follow the law of natural growth over time going through periods of birth, growth, maturity, decline, and death (Modis, 1994). This set of periods is called the life cycle of a system described by different S-shaped curves. In this way, different S-shaped curves stand for a visual symbol of cumulative growth. The best-known mathematical function that produces an S-shaped curve is called a logistic function (Kucharavy \& De Guio, 2015). This kind of S-shaped curve has many applications. Biologists have applied it to describe the growth of a species under competition. In the same way, market studies of new products, usually based on the law of natural growth in a specific niche, use S-shaped curve analysis (Modis, 1997). In this study, a specific S-shaped curve is applied at the level of the firm to analyze the behavior of profitability ratios across the life cycle stages. 
Dickinson (2011: 1970) reports that capturing life cycle at the firm level is a difficult task. She presents a review of previous studies on business life cycles and classify them at the levels of production behavior (Spence, 1977, 1979, 1981; Wernerfelt, 1985; Jovanovic \& MacDonald, 1994), learning/experience (Spence, 1981), investment (Spence, 1977, 1979; Jovanovic, 1982; and Wernerfelt 1985), entry and exit patterns (Caves, 1998), and market share (Wernerfelt, 1985). However, at the firm level life cycle is more complicated. The firm is an aggregation of multiple products, each with a different product life cycle stage. Additionally, the firm may compete in multiple industries so that its products are quite heterogeneous. Consequently, life cycle stages at the firm level are difficult to assess because they are a composite of many overlapping, but distinct product life cycle stages. Dickinson (2011) used cash-flow patterns to identify empirically five life cycle stages (introduction, growth, mature, shake-out, and decline stages) at the firm level. In this study, total expenditure acts as a proxy to reflect different life cycle stages. This kind of size measure is a common proxy for life cycle (Dickinson, 2011).

In practice, profitability is measured by profitability ratios. However, these ratios are vulnerable for obvious pitfalls (Murphy, Trailer \& Hill, 1996; Losbichler, Hofer, Eisl \& Zauner, 2012). A financial analyst can analyze time-series and cross-sectional trends in the ratios. However, in order to get a reliable view the analyst must understand the signals given by the ratios. If a firm lives in a steady state, financial ratios generate predictable profitability and investors can generally agree on its value (Ak, Dechow, Sun \& Wang, 2013). However, when the growth of the firm follows an S-shaped curve, it is important to understand the behavior of ratios in different stages of the life cycle (birth, growth, maturity, decline, and death). For example, in the early stages of development startups typically suffer from a strong nonstationary adjustment process making prediction of future profitability and valuation extremely challenging (Laitinen, 2017). Moreover, when the stage of decline and finally death (bankruptcy or decline of business) is approaching, the behavior of ratios can change giving distorted signals of profitability.

When the time-series of profitability ratios are stationary, the mean, variance and autocorrelation structure do not change over time. In this case, traditional statistical techniques can give reliable predictions of future profitability. There are several studies on the stationarity of the time-series of financial ratios (McLeay \& Stevenson, 2009; Ioannides, Peel \& Peel, 2003; Gallizo \& Salvador, 2003). This research is typically concentrated on testing stationarity assumption for mature firms, often using different adjustment models. The results are however mixed. Whittington and Tippett (1999) found that the components of financial ratios may exhibit nonstationarity whereas Ioannides, Peel \& Peel (2003) concluded that ratios are globally stationary, but that the behaviour close to equilibrium may result from a nonlinear partial adjustment process. Laitinen (2017) showed that the time-series of profitability ratios in the early stages of life cycle are non-stationary and strongly influenced by several factors such as growth, revenue lag, rate of expense, and internal rate of return (IRR). Although IRR is regarded as the principal profitability, the link of ratios to IRR is often empirically weak or potentially nonexistent and even misleading.

Profitability is often analyzed within the context of life cycle. Economic theory predicts a nonlinear progression of variables such as earnings, return on net operating assets, asset turnover, profit margin and, sales revenue across the life cycle continuum (Dickinson, 2011). For example, economic theory suggests that competitive pressures will drive mature firms to focus on efficiency and cost containment. Penman and Zhang (2006) found that increases in profit margin result in negative future return on net operating assets, since those increases are achieved through a reduction of operating expenses that are not sustainable. This effect is 
concentrated in the mature life cycle stage, where product differentiation efforts have reached diminishing returns (Oster, 1990; Shy, 1995). Thus, life cycle stages affect non-convergence of profitability over time and life cycle differences interact with the determinants of profitability. Dickinson (2011) showed that future return on net operating asset maintains a differential spread of three to 10 percent between decline and mature firms even after five years.

These profitability studies focus on explaining profitability in different life cycle stages using profitability ratios to test theories on the behavior of the firm. In this study, the objective is however to keep principal long-term profitability (defined as internal rate of return, IRR) constant and to assess the behavior of profitability ratios (as measures of the principal) in different stages of life cycle. In this way, it is possible to show to what degree the behavior of ratios is determined by the different stages only without any impact from the change of profitability (behavior). This kind of analysis can lead to better assessment of the role of growth rates and forecast horizons in valuation models and to better understanding how economic fundamentals affect the level and convergence properties of profitability. These kinds of contributions can benefit equity investors, creditors, auditors, analysts, regulators, and researchers (Dickinson, 2011).

This study extends life cycle research expanding the early stage analysis of Laitinen (2017) to the later stages of life cycle. Laitinen assumed a steady growth for the expenditure of the firm leading after the adjustment process to steady ratios. Under competition, it is usual to assume that the growth of a system like a business firm with scarce resources follows the logistic function, which leads to an S-shaped curve as a life cycle (Modis, 2007; Kucharavy \& De Guio, 2015). However, the logistic function in its basic form only describes non-negative growth process leading to non-decreasing S-shaped curve of cumulative growth. Thus, it is not practically useful when describing the decline and death stages with negative growth rates. It can be expected that the behavior of profitability ratios may change when the growth rate is changing its sign. The growth process is here assumed to consist of two parts: the stand-alone growth and the growth of competition impact, which both follow a steady path of their own. The difference of these steady growth processes describes under competition the growth of expenditure for a firm with scarce resources. When the growth rate of competition impact exceeds the stand-alone rate, an S-shaped curve with negative growth rates in the decline and death stages is resulted.

In summary, the objective of this study is to develop a growth model of a business firm under competition and analyze the behavior of profitability ratios across the stages of life cycle. Profitability is based on the ability of expenditure to generate revenue. The revenue generation is in practice a complicated process. Therefore, it is simplified in this framework assuming that the growth of periodic expenditure follows an S-shaped curve and each expenditure generates a proportionally identical flow of revenue over time. The distributed lag structure of revenue flows generated by each periodic expenditure is assumed constant over time leading to constant profitability as defined in terms of IRR. Thus, it is assumed that the firm is flexible enough to adapt its expenditure throughout the life cycle according to the S-shaped curve, without any effects on IRR or the lag structure. Then, it is assumed that the firm in each period expenses a constant part of periodic expenditure and beginning-of-the-period assets. The resulted expense is used to calculate the profit margin ratio and the return on investment ratio like in financial reporting. For comparison, the (traditional) cash flow margin ratio is calculated using the expenditure concept. Finally, the behavior of these ratios across the life cycle stages is analyzed. 
The content of the paper is organized as follows. Firstly, the introduction discussed the motivation and the objective of the study. In the second section, the analytical model of the time series of expenditure, revenue, expense and assets is constructed using simplified assumptions. In the third section, three profitability ratios are discussed under the constructed framework. Moreover, numerical experiments are carried out to show the behavior of these ratios across the life cycle stages. Furthermore, empirical data from Laitinen (2018) is used to demonstrate the results. The findings show that during the start-up (birth) stage the development of the ratios is non-stationary supporting the results presented by Laitinen (2017). Moreover, the findings show that the behavior of the ratios strongly change when the decline stage with negative growth rates begins distorting the relationship to IRR. The behavior of the ratios is largely determined by the rate of expense used by the firm in financial reporting. Therefore, the findings emphasize the importance of the expense method that should be consistent with the lag structure of revenue. Moreover, the findings show that there is a spread in profitability ratios between life cycle stages, even if the behavior of the firm does not change during its life. Finally, the last section shortly discusses the main findings of the study.

\section{Expenditure life cycle}

\section{MATHEMATICAL FRAMEWORK OF THE ANALYSIS}

The growth process of the firm is in this study assumed to consist of two separate processes following a steady state growth path of their own. The first process describes the stand-alone growth of expenditure in a situation where is no market competition at all. In this kind of simple environment, the firm with unlimited resources in the long term can follow a steady growth path. However, under competition, a firm with limited resources can lose its market share to competitors whose market power may continuously grow (Modis, 1997). The impact and timing of competition for the firm depends on the uniqueness of its products and the sustainability of the competitive advantage in the long term. Thus, the development of expenditure $E_{t}$ is described in the following way:

$$
E_{t}=E_{0}(1+g)^{t}-k E_{0}(1+d)^{t}=E_{0}\left[(1+g)^{t}-k(1+d)^{t}\right]
$$

where $g$ is the stand-alone growth rate and $k$ is the initial relative impact of competition while $d$ describes the growth rate of this impact. The expenditure growth process (1) is here used to describe the life cycle of the firm. This kind of size measure is often used as a proxy in life cycle research (Dickinson, 2011: 1974). Dickinson (2011) shows that in her sample the average size of the firms follows an S-shaped curve like defined in (1): it first increases during the introduction and growth stages but starts then to decline during the shake-out and decline stages (Table 2).

If the periodic stand-alone growth rate of expenditure equals the growth rate of the impact of competition $(g=d)$, the firm will maintain its market share $(1-k)$ and grow at the steady rate $(g)$. However, if the growth of competition impact exceeds that of the stand-alone growth rate $(d>g)$, periodic expenditure gets its maximum value in the following period $t^{*}$ :

$t^{*}=\ln \left[\frac{k \cdot \ln (1+d)}{\ln (1+g)}\right]: \ln \left[\frac{1+g}{1+d}\right]$

Thus, the higher the initial impact of competition $(k)$ or the growth rate of competition impact $(d)$, the lower is the period of maximum value $\left(t^{*}\right)$. 
The period of maximum expenditure value $\left(t^{*}\right)$ is the period when the decline stage begins. This period will last until the death stage that is here defined as the period when expenditure finally gets value of 0 . In this framework, this period $t^{0}$ is (for $d>g$ ) calculated as follows:

$t^{0}=\frac{\ln k}{\ln (1+g)-\ln (1+d)}$

when equation (1) is set equal to zero. Similarly as for $t^{*}$, the death period $t^{0}$ is lower, the higher is the initial impact of competition $(k)$ or the growth rate of competition impact $(d)$.

\section{Revenue flows}

Following Laitinen (2017), the present framework assumes that the business process of the firm is proportionally fixed and repetitive leading to that each periodic expenditure generates a similar revenue flow proportional to the size of expenditure. Therefore, the lag structure and IRR are identical for each periodic expenditure, which is a typical assumption in theoretical profitability research (Feenstra \& Wang, 2000). Thus, it is assumed that the firm is flexible and able to adapt to the impact of competition without any change in its lag structure or IRR. The impact of competition only affects the size of expenditure. It is further assumed that the lagged flows of revenue follow an infinite geometric distribution giving the following result in period $t$ for total revenue $R_{t}$ :

$$
\begin{aligned}
& R_{t}=K \cdot E_{0} \cdot q^{t}\left[\sum_{i=0}^{t}(1+g)^{i} q^{-i}-k \cdot \sum_{i=0}^{t}(1+d)^{i} q^{-i}\right] \\
& =K \cdot E_{0}\left[\frac{(1+g)^{t+1}-q^{t+1}}{1+g-q}-k \cdot \frac{(1+d)^{t+1}-q^{t+1}}{1+d-q}\right]
\end{aligned}
$$

where $K$ is the level parameter of the lagged revenue distribution whereas $q$ is the lag parameter describing the geometric lag structure. These assumptions allow us to analyze the behavior of ratios per se without effects of a change of IRR. Since firms may alter their behavior during life cycle stages (Wernerfelt, 1985; Selling \& Stickney, 1989; Penman \& Zhang, 2006; Dickinson, 2011), these kinds of ceteris paribus effects are empirically difficult to identify.

When it is assumed that the geometric revenue lag distribution is infinite, IRR or $r$ as the principal measure of profitability can be incorporated in the model in the following way:

$$
\begin{aligned}
& K \cdot E_{0}(1-k) \sum_{i=0}^{\infty} q^{i}(1+r)^{-i}=E_{0}(1-k) \\
& K=\frac{1+r-q}{1+r}
\end{aligned}
$$

using the definition of IRR. $K$ is an increasing function of $r$, so that the level of revenue flow is higher, the higher is IRR. This flow is lower, the lower is $q$ or the longer is the revenue lag.

When $K$ in equation (5) is substituted in (4), the periodic revenue $R_{t}$ can be presented as:

$$
R_{t}=E_{0}\left[\frac{1+r-q}{1+r}\right]\left[\frac{(1+g)^{t+1}-q^{t+1}}{1+g-q}-k \cdot \frac{(1+d)^{t+1}-q^{t+1}}{1+d-q}\right]
$$

which can reach a steady growth path with growth rate $g$ only when there does not exist competition impact at all $(k=0)$ or when this impact grows at the same rate as the stand-alone expenditure $(d=g)$. In these special cases, the steady ratio of $R_{t}$ to $E_{t}$ is as follows: 
that is symmetric with respect to $r$ and $g$ and equals equality (4) in Laitinen (2017). This ratio also depends on the lag parameter $q$ which tells how quickly invested expenditure will generate revenue. This lag is increasing in $q$ with an average lag of $q /(1-q)$. This revenue lag is conceptually close to the asset turnover that is one of the determinants of future profitability (see Dickinson, 2011).

\section{Expenses and assets}

Limited business firms must periodically prepare income statement and balance sheet according to the accounting law, conventions and doctrine. These financial statements are used in financial statement analysis to assess the profitability of the firm. The going concern convention on continuity of activity assumes that the business will be operating indefinitely. Moreover, the doctrine of consistency requires financial statements for different accounting periods be based on the same accounting principles to make financial results comparable over periods. These general rules justify an assumption that certain accounting parameters are practically fixed over time (Laitinen, 2017). Therefore, it is assumed that the firm periodically expenses a fixed proportion $C$ of expenditure and non-expensed expenditure (asset) in the balance sheet. This systematic accounting procedure leads to the following time series of expense $D_{t}$ :

$$
\begin{aligned}
& D_{t}=C \cdot E_{0} \sum_{i=0}^{t}\left[(1+g)^{i}(1-C)^{t-i}-k \cdot(1+d)^{i}(1-C)^{t-i}\right] \\
& =C \cdot E_{0}\left[\frac{(1+g)^{t+1}-(1-C)^{t+1}}{g+C}-k \cdot \frac{(1+d)^{t+1}-(1-C)^{t+1}}{d+C}\right]
\end{aligned}
$$

which shows that the periodic expense $\left(D_{t}\right)$ is determined by the growth process of expenditure $\left(E_{0}\right)$ and the rate of expense $\mathrm{C}$.

The assets of the firm directly follow from the accounting identity based on the definition of the expense concept: assets are drawn up from the unexpired expenditure. This systematic procedure leads to the following expression for the time series of assets $A_{t}$ :

$$
\begin{aligned}
& A_{t}=(1-C) \cdot E_{0} \sum_{i=0}^{t}\left[(1+g)^{i}(1-C)^{t-i}-k \cdot(1+d)^{i}(1-C)^{t-i}\right] \\
& =(1-C) \cdot E_{0}\left[\frac{(1+g)^{t+1}-(1-C)^{t+1}}{g+C}-k \cdot \frac{(1+d)^{t+1}-(1-C)^{t+1}}{d+C}\right]
\end{aligned}
$$

which together with equation (8) shows that:

$$
A_{t}=D_{t} \cdot \frac{1-C}{C}
$$

In equations (8) and (9), the rate of expense $C$ is not specified. In annual closing of accounts, the firm can select $C$ in the flexibility limits of expense management (Choy, 2012). These flexibility limits are drawn from accounting legislation and GAAP. In this kind of theoretical framework, it is possible to consider different expense methods specifying $C$ correspondingly (Laitinen, 2018). For example, it can be assumed that the expiration of expenditure as expenses 
follows in time the lag structure of revenue resulting in that $C=1-q$. This kind of method is largely consistent with accounting standards where expenses are recognized in the income statement when a decrease in future benefits related to a decrease in an asset has arisen that can be measured reliably (IASB Framework, paragraph 94). Laitinen (2018) reported that about $43.6 \%$ of his sample firms can be regarded as followers of this kind of expensing method.

\section{Summary}

The framework of this study is consisted of a mathematical model where a firm with limited resources is assumed to grow under competition following an S-shaped life cycle. The purpose is here to analyze the behavior of profitability ratios across different stages of this kind of life cycle. Generally, profitability is theoretically associated with IRR used as the principal object for measurement (Feenstra \& Wang, 2000). Since the analysis deals with the (surrogate) measures of profitability (ratios), the behavior of ratios is analyzed keeping the principal profitability (IRR or $r$ ) and the lag structure $(q)$ constant over time, in order to separate the pure effect of life cycle stages. Therefore, the analysis is performed using the ceteris paribus (other things being equal) assumption that is common in economic research (Boumans \& Morgan, 2001).

Thus, the framework conceptually depicts a business firm that is flexible enough to adapt to changes in expenditure (size) during its life cycle, without any changes in IRR or $q$. These kinds of assumptions give a possibility to draw some simplified conclusions for the behavior of profitability ratios across the life cycle stages. Especially, it is possible on ceteris paribus conditions to analyze the degree to which the life cycle stages alone, based on growth of expenditure, can explain the spread in profitability ratios without changes in the principal profitability, IRR. This kind of analysis is justified, because even for a constant IRR, profitability ratios can potentially show spread across the life cycle stages. These kinds of findings about the ceteris paribus effects on the spread may contribute to the discussion on the relation of profitability and life cycle stages (Dickinson, 2011).

\section{Cash flow margin ratio}

\section{BEHAVIOR OF PROFITABILITY RATIOS}

This analysis will deal with three profitability ratios. The most simple profitability ratio in this framework is the traditional cash flow margin ratio (quick flow) referring to the difference between periodic revenue $R_{t}$ and periodic expenditure $E_{t}$. It is not based on any expense concept neglecting the causal relationship between expenditure and the flow of revenue in financial reporting. This ratio $\left(\mathrm{CFM}_{\mathrm{t}}\right)$ can be presented in the following form:

$$
C F M_{t}=\frac{R_{t}-E_{t}}{R_{t}}=1-\frac{E_{t}}{R_{t}}
$$

which can be calculated substituting equations (1) and (6) in (11). In fact, $\mathrm{CFM}_{\mathrm{t}}$ is rather a measure of the sufficiency of revenue finance than profitability.

Because the accumulation of periodic revenue $R_{t}$ follows the distributed lag structure, it is in the early periods very low in comparison with expenditure $E_{t}$. This slow accumulation of revenue leads to a low $\mathrm{CFM}_{t}$ in the birth and early growth stages according to equation (11). When periodic expenditure continues to grow, the revenue generation process will go on, and finally $R_{t}$ will increase to approach the level determined by IRR, $q, g, k$ and $d$. Laitinen (2017) has described this kind of early adjustment process for a startup growing at a steady rate. In this case, $\mathrm{CFM}_{\mathrm{t}}$ will reach with the passage of time the following steady level: 


$$
C F M_{t}=\frac{q(r-g)}{(1+g)(1+r-q)}
$$

which is got in the present framework in the special cases when $k=0$ or $d=g$. Equation (12) clearly shows the effect of $r, g$, and $q$ on $\mathrm{CFM}_{\mathrm{t}}$.

When the growth of expenditure instead of steady growth follows an S-shaped curve, any steady state for $\mathrm{CFM}_{\mathrm{t}}$ cannot be reached. However, even in this case, the time-series of $\mathrm{CFM}_{\mathrm{t}}$ will stabilize after the birth stage. In this general case, expenditure continues to grow, revenue generation process will get its full rate and $\mathrm{CFM}_{t}$ may stay relatively constant for a while (growth and mature stage). However, when the firm enters to the decline stage, the behavior of $\mathrm{CFM}_{\mathrm{t}}$ is expected to change strongly. In this stage, $E_{t}$ will diminish but due to the lagged revenue structure, $R_{t}$ will decline more slowly. Therefore, during the decline stage, CFM $\mathrm{t}$ tends to increase. Thus, this kind of increase in $\mathrm{CFM}_{t}$ is in this framework not a signal of improved profitability but a result of diminished expenditure and a realization of lagged revenues. It should be clearly observable for a constant IRR. When IRR $(r)$ is ceteris paribus increased; it only affects the scale coefficient $K$ in (5) without any impact on the form of time-series. Therefore, an increase in IRR will only rise the level of the time-series of $\mathrm{CFM}_{\mathrm{t}}$. This kind of behavior of CFMt is in line with Dickinson (2011) who links cash flow patters to life cycle stages assuming that in the introductory stage operating and investing cash flows are negative whereas investing and financing cash flows are positive in the decline stage (Table 1).

\section{Profit margin ratio}

When matching periodic revenue and expenditure, cash flow margin ratio does not recognize the causal relationship between expenditure and the flow of lagged revenues. It is not based on the profit concept as accrual ratios and is therefore independent of the expense method. In practice, profitability of the firm is usually measured by accrual ratios, mainly by the profit margin ratio and the return on investment ratio (Murphy, Trailer \& Hill, 1996; Losbichler, Hofer, Eisl \& Zauner, 2012). These measures are the main types of profitability ratios that can aid an in-depth understanding of the business of a firm. In this framework, profit margin ratio $\left(\mathrm{PMR}_{\mathrm{t}}\right)$ is defined as the ratio of profit (revenue - expense) to revenue as follows:

$$
P R M_{t}=\frac{R_{t}-D_{t}}{R_{t}}=1-\frac{D_{t}}{R_{t}}
$$

which can be calculated substituting equations (6) and (8) in (13).

Profit margin ratio is sensitive to the expense method (rate of expense $C$ ) employed by the firm, since it determines the level of $D_{t}$. In a special case, when the expiration of expenditure as expenses in time follows exactly the lag structure of revenue making the rate of expense $C=1$ $q$, profit margin ratio $\mathrm{PRM}_{\mathrm{t}}$ is reduced to the following form:

$$
P R M_{t}=\frac{r(1-C)}{r+C}=\frac{r \cdot q}{1+r-q}
$$

which is constant throughout all stages of the life cycle. This equation is equal to (13) in Laitinen (2017) drawn for startups. In this special case, the level of the constant ratio is sensitive to IRR but also to the lag parameter $(q)$. Thus, it is not a valid measure of profitability because of the effect of the lag structure that can strongly differ between industries. 
In practice, the selection of $C$ to be equal to 1-q requires careful tracking of asset usage and ability to estimate total usage over the life of the asset. The larger the deviation of selected $C$ from 1-q, the stronger can the effect of life cycle stages be on the time series of $\mathrm{PRM}_{\mathrm{t}}$. If $C>1-q$, then the firm expenses (expires) more expenditure than is allowed by the lag structure. This kind of accelerated expense rate will in the early years (birth stage) result in a very low but increasing $\mathrm{PRM}_{t}$, since expenses accumulate faster than revenues. However, $\mathrm{PRM}_{t}$ will maintain a quite stable level in the growth stage when the revenue generation process acts at the full rate. When periodic expenditure starts to diminish in the decline stage, accelerated expenses decline more rapidly than lagged revenue, which makes $\mathrm{PRM}_{\mathrm{t}}$ increase in the last years. If $C<$ 1- $q$, expenses are decelerated, and the behavior of $P R M_{t}$ is reversed: $P_{R M}$ may in the early (birth) stage be exceptionally high due to decelerated expenses, then stabilize (growth and mature stages), and finally diminish (decline stage) before death. Empirically, Dickinson (2011) reported that in her sample average $\mathrm{PRM}_{t}$ is negative in both the introduction and decline stages (Table 2).

\section{Return on investment ratio}

Profit margin ratio is calculated using profit and revenue flows without paying attention to the assets of the firm. However, assets are taken into account by the return on investment ratio (ROI) that is in practice the most widely adopted measure of profitability (Losbichler, Hofer, Eisl \& Zauner, 2012). It is also considered a proxy of IRR in theoretical analyses (Feenstra \& Wang, 2000). This profitability ratio calculated on-the-beginning-of-period basis can be presented as follows:

$$
\begin{aligned}
& R O I_{t}=\frac{R_{t}-D_{t}}{A_{t-1}}=\left[\frac{R_{t}}{A_{t}}-\frac{C}{1-C}\right]\left(1+g_{t}^{A}\right) \\
& =\frac{C}{1-C}\left[\frac{R_{t}}{D_{t}}-1\right]\left(1+g_{t}^{A}\right)
\end{aligned}
$$

where $g_{t}^{A}$ is the growth rate of assets in period $t$. This ratio can be calculated in this framework substituting equations (4), (8) and (9) in (15).

The lower part of (15) shows that the time series of ROI behaves over time in a very similar way as PRM $_{t}$. However, it is also affected by the growth rate of assets. The relationship between the profitability ratios can be expressed as follows:

$$
R O I_{t}=\frac{C}{1-C}\left[\frac{P R M_{t}}{1-P R M_{t}}\right]\left(1+g_{t}^{A}\right)
$$

substituting equation (11) in (15). When the growth of assets $g_{t}^{A}$ is positive and very high in the first years (birth and beginning of growth); it will in these stages strengthen the increase $(C$ $>1-q)$ and dampen the decrease of the ratio $(16)(C \leq 1-q)$ in comparison to PRM $_{\mathrm{t}}$. Similarly, when $g_{t}^{A}$ is negative and very low in the last years (decline stage); it will in this stage strengthen the decrease $(C \leq 1-q)$ and dampen the increase of the ratio (16) $(C>1-q)$. Empirically, Dickinson (2011) showed that the average return on net operating assets ratio is negative in both the introduction and decline stages.

If the firm systematically selects to make expenses to follow accumulation of revenues as $C=1$ $q$, then $\mathrm{ROI}_{\mathrm{t}}$ will simplified in the following way: 
$R O I_{t}=\frac{R_{t}-D_{t}}{A_{t-1}}=r \cdot \frac{1+g_{t}^{A}}{1+r}$

which is not constant but changes over time with the growth of assets. Because of the effect of asset growth, $\mathrm{ROI}_{\mathrm{t}}$ in this case is not a valid measure of profitability $r$. If ROI $\mathrm{I}_{\mathrm{t}}$ is however defined on the end-of-period basis (using $A_{t}$ instead of $A_{t-1}$ ), it is constant over life cycle stages as follows:

$R O I_{t}=\frac{R_{t}-D_{t}}{A_{t}}=\frac{r}{1+r}$

which gives only a slightly biased estimate of IRR.

\section{Numerical experiments}

The behavior of the three profitability ratios throughout the life cycle can be demonstrated using numerical experiments. For the experiments, let us firstly assume that $r=0.10$ and $q=$ 0.35, which correspond to the average values of Finnish firms (Laitinen, 2018: Table 4). Moreover, let $E_{0}=100, k=0.15, g=0.05, d=0.07$, and $C=0.65$. In this base case, the market power of competitors is first $15 \%$ but it grows faster than the expenditure of the exemplary firm $(d>g)$ leading to an S-shaped curve of $E_{t}$. It is also assumed that $C=1-q$ so that the expiring of expenditures as expenses is consistent with the revenue lag structure. Table 1 presents a summary of the results for this base case (case 1). Using these parameter values, the exemplary firm will live about 100 periods $\left(t^{0}=100.54\right)$ according to equation (3). This firm will show positive rates of growth until the beginning of the decline stage in period $83\left(t^{*}=\right.$ 83.22) following equation (2).

Table 1. Experiments with the parameters of the model.

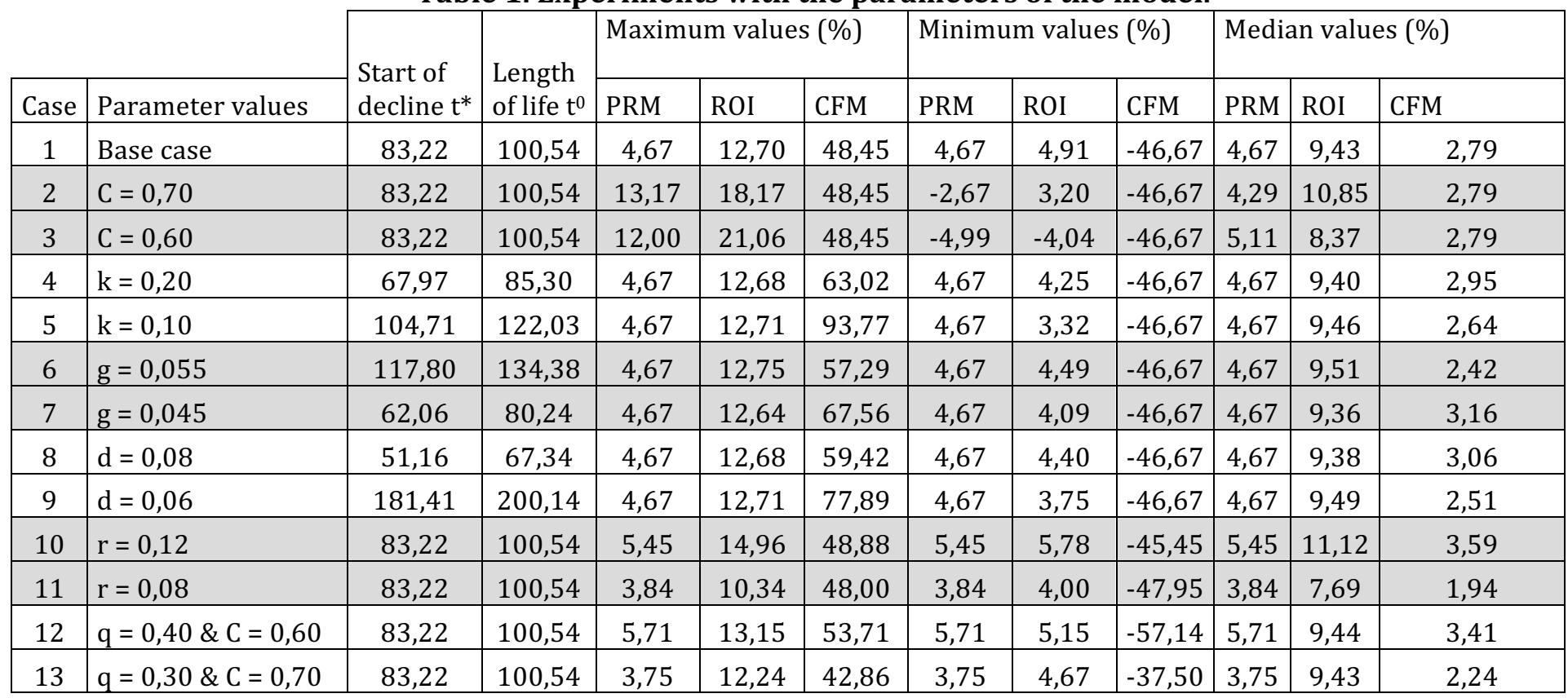

Legend:

\begin{tabular}{|l|c|c|c|c|c|c|c|}
\hline Base case & $\mathrm{E}_{0}$ & $\mathrm{k}$ & $\mathrm{g}$ & $\mathrm{d}$ & $\mathrm{C}$ & $\mathrm{r}$ & $\mathrm{q}$ \\
\hline & 100,00 & 0,1500 & 0,0500 & 0,0700 & 0,6500 & 0,1000 & 0,3500 \\
\hline
\end{tabular}


Figure 1 shows the time-series of $E_{t}$ and $R_{t}$ for the base case (case 1 ) while appendix 1 presents the numerical values of model variables for 100 periods. In this case, the average revenue lag is only $0.35 /(1-0.35)=0.54$ periods. Therefore, revenue $R_{t}$ is growing quickly and exceeds $E_{t}$ already in period 3. However, when the growth of $E_{t}$ starts to slow down already before the decline stage, $R_{t}$ starts to exceed $E_{t}$ more clearly due the lagged revenue flows. Figure 2 presents the time-series of the three profitability ratios. This figure shows that $\mathrm{CFM}_{\mathrm{t}}$ is very low in the first periods (during the adjustment process) but stabilizes quickly when the revenue generating process maintains its full rate. When $E_{t}$ starts to slow down, $\mathrm{CFM}_{\mathrm{t}}$ starts to rise and is very high in the last periods of the decline stage. Because in this base case $C=1-q$, $\mathrm{PRM}_{t}$ is constant (4.7\%) throughout the stages of the life cycle according to equation (14). $\mathrm{ROI}_{\mathrm{t}}$ is in the first years high but after this adjustment (birth) stage, it stays quite stable until the start of the decline stage when the ratio starts quickly to diminish. The spread in the value of ROI $_{t}$ during the birth and decline stages is however not wide: the maximum value is $12.7 \%$ (period 1) while the minimum value is $4.9 \%$ (period 100). The median value of $\mathrm{ROI}_{\mathrm{t}}(9.4 \%)$ is to some degree below IRR underestimating $r$. If an end-of-period value of assets is used in ROI following equation (18), the ratio is constant (9.09\%) but underestimates $r$ even more clearly than this median.

Figure 1. Time-series of expenditure and revenue (cases 1-4, 10-13).

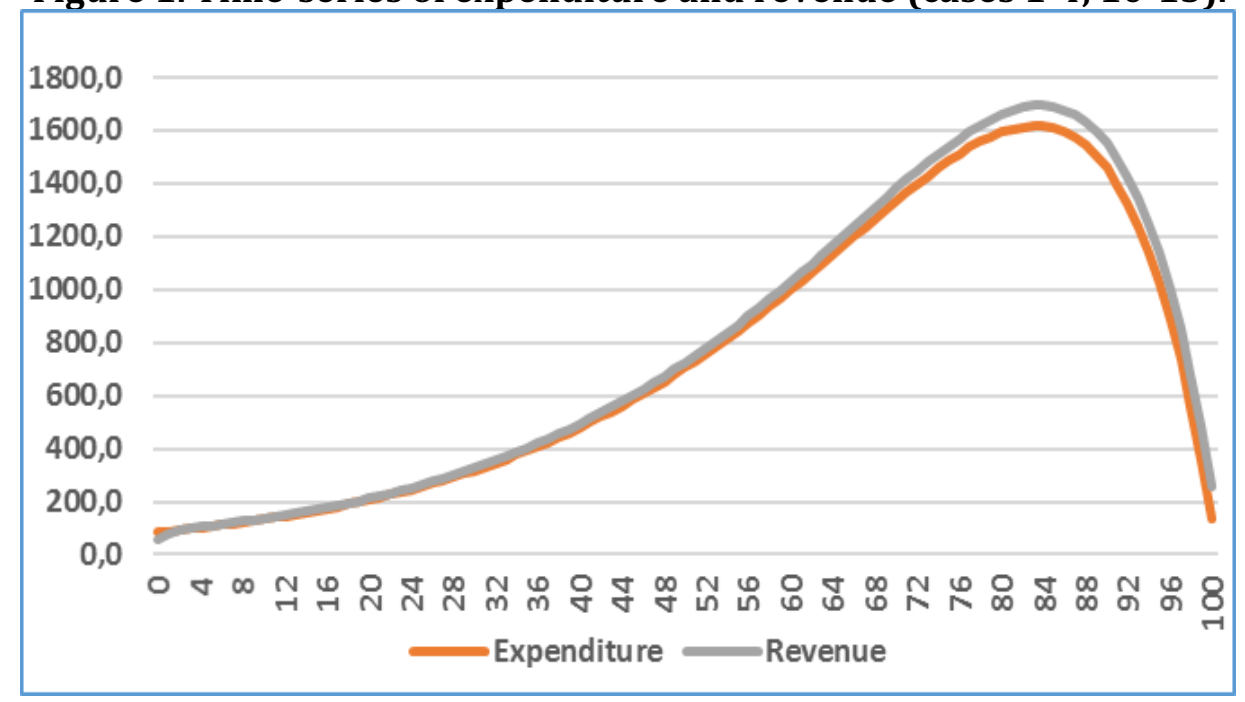


Figure 2. Development of profitability ratios in the base case (case 1).

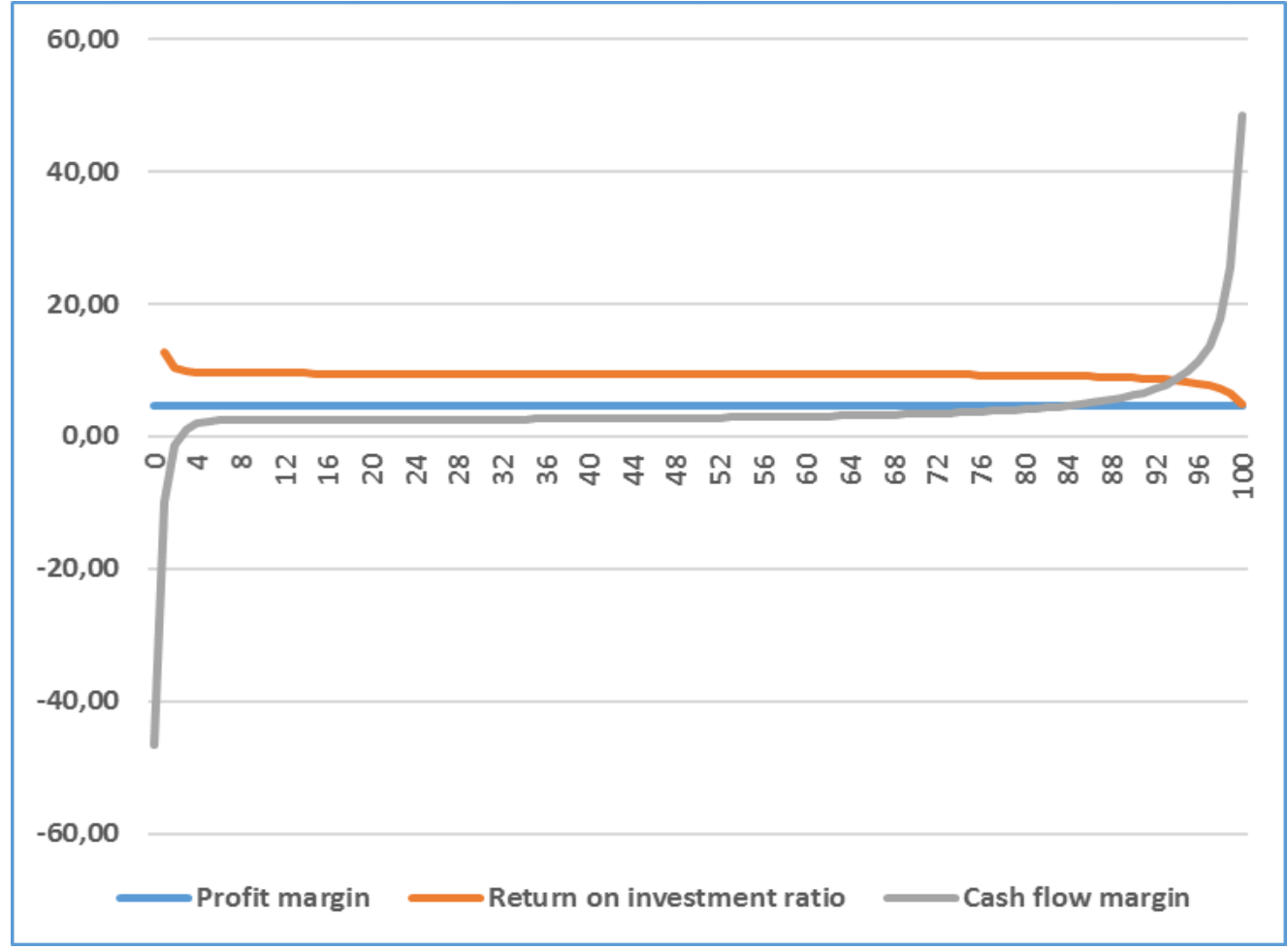

Cases 2 and 3 in Table 1 show the ceteris paribus effects of the rate of expense $C$. CFM $\mathrm{t}_{\mathrm{t}}$ is independent of $C$ and is thus insensitive to these effects. In case $2, C>1-q(C=0.7)$ which means that the firm expenses in financial reporting more than is allowed by the revenue lag structure. The behavior of profitability ratios in this case is presented in Figure 3 . PRMt and ROI show large variations (spread) but in a reversed way when compared with case 1: the ratios are low in the birth stage and, respectively, high in the decline stage. $\mathrm{PRM}_{t}$ even shows negative values in the early stages. The median value of ROI $_{t}(10.9 \%)$ exceeds IRR overestimating $r$ whereas the median $\mathrm{PRM}_{\mathrm{t}}$ is lower than in case 1 . In case $3, C<1-q(C=0.6)$ so that the firm expenses less than allowed by the lag structure. Figure 4 shows that $\mathrm{PRM}_{t}$ and ROI behave in a reversed way in comparison with case 2: the ratios are high in the birth stage and low in the decline stage. The spread is large, since both ratios are very high in the birth stage but show negative values before the death stage. The median value of ROI $(8.4 \%)$ clearly underestimates $r$ whereas that of $\mathrm{PRM}_{\mathrm{t}}$ exceeds the median values calculated in case 1 and 2 . 
Figure 3. Development of profitability ratios in case $2(C=0,70)$.

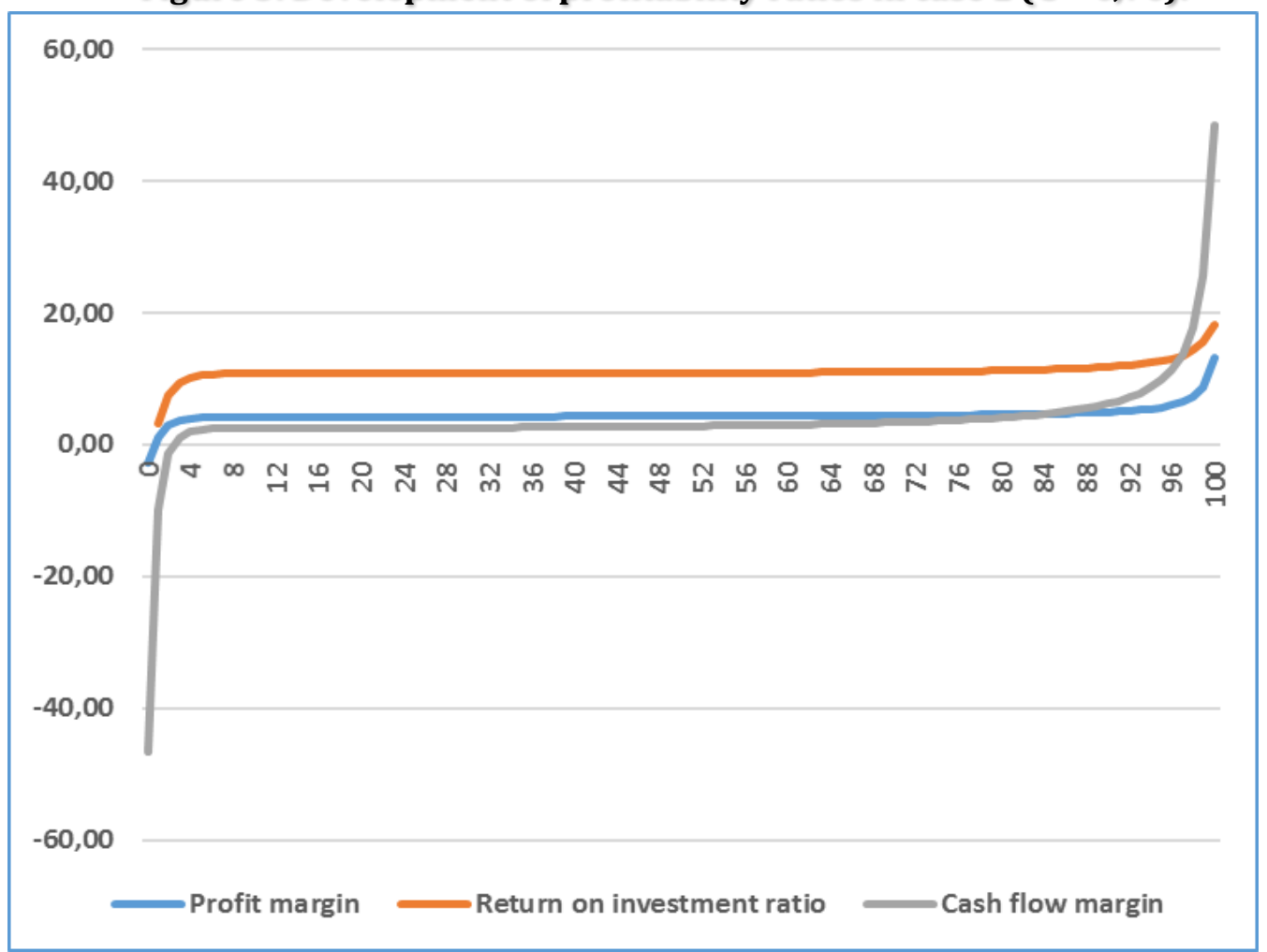

Figure 4. Development of profitability ratios in case $3(C=0,60)$.

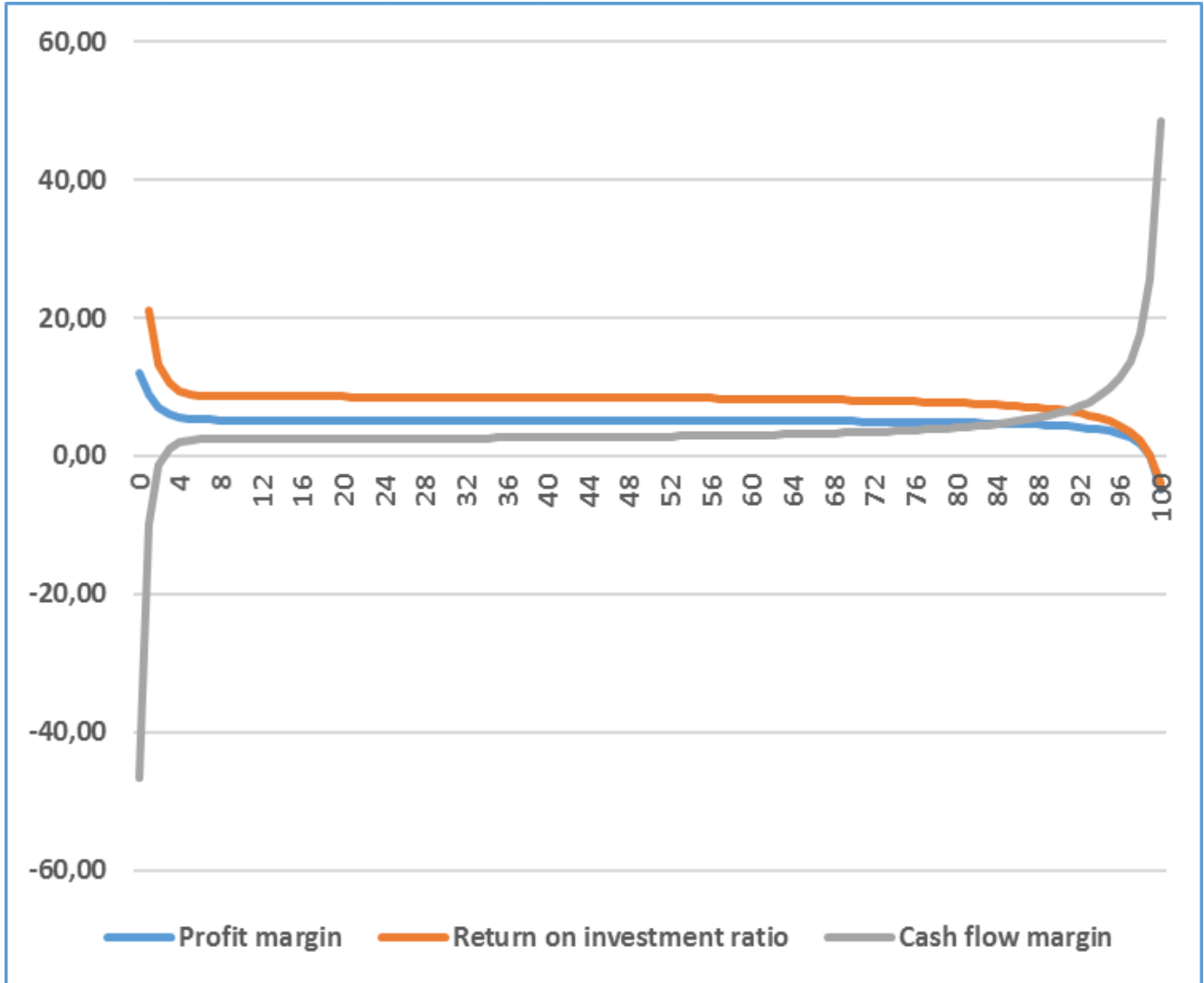

For cases $4-13, C$ is set equal to $1-q$, so that $\mathrm{PRM}_{\mathrm{t}}$ is constant throughout the life cycle stages. Cases 4-9 describe the ceteris paribus effects of the growth parameters $(k, g$, and $d)$ on the profitability ratios. $\mathrm{PRM}_{t}$ is independent of these effects. However, they have a weak effect on 
the median value of ROI $\mathrm{I}_{\mathrm{t}}$ but a stronger effect on that of CFM $\mathrm{t}_{\mathrm{t}}$. Especially, all changes in these parameters have an impact on spread increasing the maximum value of $\mathrm{CFM}_{t}$ and decreasing the minimum value of ROI. Cases 10 and 11 demonstrate the ceteris paribus effects of $r$. The levels of $\mathrm{PRM}_{\mathrm{t}}$ and ROI $\mathrm{t}$ are sensitive to these effects of IRR: the higher $r$, the higher are the maximum, minimum and median values of these ratios. However, the behavior of the ratios during the different life cycle stages follow the lines of the base case. In these cases, the median values of ROI $(11.1 \%$ and 7.7\%) again underestimate IRR. The effects of $r$ on the median value of $\mathrm{CFM}_{\mathrm{t}}$ are similar as for other ratios; however, the effects on the maximum and minimum values (spread) are weak. Finally, cases 12 and 13 present the ceteris paribus effects of $q$ (keeping $C=1-q$ ). These effects of $q$ on $\mathrm{PRM}_{\mathrm{t}}$ and $\mathrm{CFM}_{\mathrm{t}}$ are strong: the higher $q$, the higher are the ratios. However, the effects of $q$ on $\mathrm{ROI}_{\mathrm{t}}$ are relatively weak and the median values are almost identical with that of the base case $(9.43 \%)$.

\section{Empirical figures}

The pure effects of life cycle stages are empirically very difficult to identify because of the multitude of factors affecting profitability ratios. However, in this context a summary of empirical figures are presented to demonstrate the concepts of the study. In this analysis, the data used by Laitinen (2018) is employed for demonstration purposes only. These data only include older firms so that the birth (startup) stage is excluded from the analysis. However, this early stage is carefully analyzed by Laitinen (2017) using similar concepts as in this study. The data used in this study are carefully discussed in Laitinen (2018: section 3) so that only a summary will be presented. The final data after deleting firms with missing values consist of 619 firms with nine-year time-series of financial variables. These firms are from different industries. Nine-year time-series are used to estimate (restricted LS) the main parameters of the revenue-generating process $(r, q)$ to get an estimate for IRR and the revenue lag. Moreover, a proxy of growth rate for the nine-year period is estimated (ordinary LS) as a steady rate and the rate is expense $(C)$ is calculated as a weighted average over the period (see Laitinen, 2018: section 3).

The sample firms are classified according to growth of expenditure into three different stages of life cycle. First, firms with growth rate higher than $1 \%$ are considered growth firms. Second, firms with growth rate between $+1 \%$ and $-1 \%$ are regarded as mature firms and finally, firms with growth rate less than $-1 \%$ are declining firms. Table 2 presents the percentiles of the estimates by the life cycle stage. For the mature firms, growth process is random and cannot be explained by any logarithmic-linear trend. For the declining firms, revenue is diminishing less quickly than expenditure conforming the findings about the lagged revenue structure. The median cash flow ratio (CFR) is negative for the growth firms, close to zero in mature firms, and positive for the declining firms, which is in line with the findings of this study and with Dickinson (2011: 1974). Moreover, the median profit margin ratio (PRM) and the median return on investment ratio (ROI) are highest in growth firms and lowest in declining firms being comparable with Dickinson (2011: 1976). 
Table 2. Summary of empirical estimation results (n=631 firms)

\begin{tabular}{|c|c|c|c|c|c|c|c|c|c|c|c|}
\hline & \multicolumn{11}{|c|}{ Percentiles: } \\
\hline & \multicolumn{3}{|c|}{ Growth stage $(n=374)$} & \multicolumn{3}{|c|}{ Maturity stage $(n=92)$} & \multicolumn{3}{|c|}{ Decline stage $(n=165)$} & \multicolumn{2}{|c|}{ Median test } \\
\hline & 25 & 50 & 75 & 25 & 50 & 75 & 25 & 50 & 75 & Chi-Square & $\mathrm{p}$-value \\
\hline Growth of total expenditure $E_{t}$ & 0,027 & 0,044 & 0,073 & $-0,003$ & 0,002 & 0,005 & $-0,065$ & $-0,042$ & $-0,025$ & 432,229 & 0,000 \\
\hline $\mathrm{R}^{2}$ of steady growth equation $\S$ & 0,303 & 0,583 & 0,786 & 0,002 & 0,008 & 0,035 & 0,189 & 0,400 & 0,657 & 114,212 & 0,000 \\
\hline Growth of total revenue $R_{t}$ & 0,025 & 0,043 & 0,073 & $-0,005$ & 0,003 & 0,011 & $-0,062$ & $-0,039$ & $-0,023$ & 362,407 & 0,000 \\
\hline $\mathrm{R}^{2}$ of steady growth equation $\S$ & 0,374 & 0,664 & 0,849 & 0,011 & 0,060 & 0,156 & 0,222 & 0,487 & 0,760 & 95,234 & 0,000 \\
\hline Weighted growth rate & 0,026 & 0,043 & 0,071 & $-0,003$ & 0,003 & 0,007 & $-0,064$ & $-0,040$ & $-0,023$ & 412,503 & 0,000 \\
\hline Weighted cash flow ratio CFR & $-0,061$ & $-0,021$ & 0,027 & $-0,013$ & 0,013 & 0,040 & 0,017 & 0,053 & 0,086 & 111,314 & 0,000 \\
\hline Weighted profit margin ratio PMR & 0,025 & 0,049 & 0,083 & 0,014 & 0,031 & 0,056 & $-0,001$ & 0,020 & 0,041 & 53,108 & 0,000 \\
\hline Weighted return on investment ratio ROI & 0,069 & 0,142 & 0,304 & 0,038 & 0,079 & 0,135 & $-0,002$ & 0,059 & 0,120 & 59,827 & 0,000 \\
\hline Estimated internal rate of return IRR $(r)$ & $-0,049$ & 0,027 & 0,086 & $-0,033$ & 0,037 & 0,132 & 0,012 & 0,102 & 0,314 & 18,737 & 0,000 \\
\hline $\mathrm{R}^{2}$ of IRR lagged estimation equation\& & 0,850 & 0,945 & 0,970 & 0,629 & 0,821 & 0,939 & 0,848 & 0,938 & 0,974 & 25,375 & 0,000 \\
\hline Estimated revenue lag $q$ & 0,189 & 0,366 & 0,579 & 0,110 & 0,227 & 0,446 & 0,149 & 0,273 & 0,397 & 20,735 & 0,000 \\
\hline $1-q$ & 0,421 & 0,634 & 0,811 & 0,554 & 0,774 & 0,890 & 0,603 & 0,727 & 0,851 & 21,323 & 0,000 \\
\hline Weighted rate of expense $C$ & 0,613 & 0,709 & 0,802 & 0,605 & 0,708 & 0,792 & 0,632 & 0,743 & 0,828 & 3,541 & 0,170 \\
\hline$(1-q) / C$ & 0,616 & 0,923 & 1,129 & 0,860 & 1,081 & 1,205 & 0,809 & 0,984 & 1,170 & 16,993 & 0,000 \\
\hline Age of the firm\# & 19,0 & 27,0 & 42,0 & 19,3 & 29,0 & 61,8 & 18,3 & 25,5 & 53,0 & 2,548 & 0,280 \\
\hline Total expenditure $E_{t} \#$ & 21442 & 53570 & 136346 & 17195 & 44569 & 124985 & 16503 & 35058 & 103043 & 9,830 & 0,007 \\
\hline Total revenue $\mathrm{R}_{\mathrm{t}} \#$ & 23308 & 56849 & 144413 & 18241 & 45685 & 128066 & 18559 & 35358 & 107698 & 9,088 & 0,011 \\
\hline Number of employees\# & 117 & 220 & 489 & 90 & 179 & 446 & 91 & 162 & 390 & 6,630 & 0,036 \\
\hline
\end{tabular}

Legend:

$\S=$ Laitinen (2018), Equation 25

$\&=$ Laitinen (2018), Equation 26

\# = Last available year

However, the rank order of the median estimated IRR is reversed to that of the median profitability ratios: it is lowest in growth firms and clearly highest in declining firms. This kind of result about profitability has similarities with findings of Anthony and Ramesh (1992) using the concept stagnant instead of declining firms. The differences between reported profitability ratios and IRR are due to the differences in revenue lag structure and the rate of expense employed by the firms. The median rates of expense $(C)$ are almost equal in different stage classes. However, the median revenue lag parameter $(q)$ is clearly highest in growth firms reflecting low asset turnover. Consequently, growth firms has expired much more expenses than allowed by the lag structure (1-q) while mature firms with a low lag parameter have expired less. Thus, the relationship between IRR and reported profitability ratios is distorted by differences in growth (life cycle stage), revenue lag (asset turnover), and rate of expense.

\section{CONCLUDING REMARKS}

The objective of this study was to develop a mathematical model of a firm with limited resources under competition in order to analyze the behavior of profitability ratios across the stages of life cycle. It was assumed that the growth of periodic expenditure is following an Sshaped curve and each expenditure generates a proportionally identical flow of revenue over time. The lag structure of revenue flows was assumed constant and consistent with an infinite geometric distribution. Furthermore, the model assumed that IRR is constant throughout the life cycle stages. These kinds of assumptions are typical for profitability research on IRR 
(Feenstra \& Wang, 2000). Consistently with the lag structure, it was assumed that the expense rate used by the firm is fixed in time leading to a geometric expense distribution over periods. The behavior of three profitability ratios (profit margin ratio, return on investment ratio, and cash flow margin ratio) during the life cycle of the firm was analyzed in this simplified framework.

It was shown that although IRR is constant, profitability ratios show a remarkable spread during the birth stage and after the beginning of the decline stage. This means that at least part of the spread of profitability ratios between life cycle stages is caused by the S-shaped growth curve of size (here, expenditure). This part of spread is independent of the behavioral changes in the firms leading to changes in principal profitability as suggested by previous studies (Wernerfelt, 1985; Selling \& Stickney, 1989; Penman \& Zhang, 2006; Dickinson, 2011). Therefore, it can be proposed that when analyzing the development of profitability ratios to assess the company value, it would be important to pay attention to the growth of size, since the life cycle stage alone can explain at least part of the spread in ratios. In this context, attention should also be paid to the expensing method used by the target firm. The role of growth may also give an explanation why empirical findings on the behavior of profitability ratios between life cycle stages differ from each other. Consistently with this study, Dickinson (2011) finds that the size begins to decline after the mature stage whereas Anthony \& Ramesh (1992), however, find that size will increase until the end of the final stagnant stage leading to that profitability ratios will improve all the time.

In general, the cash flow margin ratio shows a very high spread in life cycle stages: in the birth stage, this ratio is negative and very low, then quite stable during the growth stage, and finally very high in the decline stage near to the death. The behavior of the profit margin ratio and the return on investment ratio greatly depends on the rate of expense used by the firm: if the rate of expense is consistent with the lag structure of revenue, the variations in the return on investment ratio are relatively low and the profit margin ratio is constant across the life cycle stages. Even in this ideal case, the return on investment ratio is not an accurate measure of IRR (compare with Feenstra \& Wang, 2000). When the expense rate is not consistent with the lag structure, the spreads in the ratios greatly increase during the birth and decline stages. If the rate of expense is higher (lower) than it is allowed by the lag structure, the median profit margin ratio will decline (increase) whereas that of the return on investment ratio will increase (decrease) and overestimate (underestimate) IRR. Furthermore, when the rate of expense is high (low), the ratio will be very low (high) in the birth stage and very high (low) in the decline stage.

Thus, the findings of this study are consistent with the results of Laitinen (2017) on the behavior of profitability ratios of a startup in the early stages. However, the present analysis extends the analysis for the whole life cycle of the firm to contribute to life cycle research. This study showed that during the growth stage, profitability ratios are quite stabilized but when the decline stage begins, great variations are expected. These variations can be dampened using a rate of expense that is consistent with the revenue lag. In principle, this kind of expensing method is consistent with the IASB where expenses are recognized in the income statement when a decrease in future benefits related to a decrease in an asset has arisen that can be measured reliably (IASB Framework, paragraph 94). In practice, it is one of the most accurate expense methods in matching expenses with revenue but requires careful tracking of asset usage and ability to estimate total usage over the life of the asset. If the rate of expense selected by the firm is too high or too low, it leads to remarkable spread in profitability ratios when the growth of the firm is following an S-shaped life cycle curve. 
This study gave important implications about the behavior of profitability ratios during the different life cycle stages. However, it is also exposed to several limitations that can be relaxed in further studies. Firstly, the growth of the firm was modelled using the difference of two steady growth processes to take account of competition in the market. This kind of dual description can be replaced for example by the logistic curve (Modis, 1997) or by the secondorder Pascal distribution, which both lead to an S-shaped growth curve. Secondly, this study was based on a ceteris paribus assumption keeping IRR constant during the life cycle. This assumption can be relaxed for example by letting IRR be flexible to the variations in sales or expenditure. Thirdly, this study is mainly theoretical although empirical perspective is taken into account when choosing the parameter values for the experiments and presenting related empirical evidence. In further studies, deeper empirical orientation is however needed. For example, it would be interesting to gather data from real life cycles of firms to analyze the behavior of profitability ratios in real situations. Finally, these analyses could be extended beyond the profitability ratios to deal with other types of ratios, too (see Dickinson, 2011).

\section{References}

Ak, B. K., Dechow, P.M., Sun, Y. \& Wang, A.Y. (2013). The use of financial ratio models to help investors predict and interpret significant corporate events. Australian Journal of Management. 38(3). 553-598.

Anthony, J. \& Ramesh, K. (1992). Association between accounting performance measures and stock prices. Journal of Accounting and Economics. 15(2-3). 203-227.

Boumans, M. \& Morgan, M.S. (2001). Ceteris paribus conditions: materiality and the application of economic theories. Journal of Economic Methodology. 8(1). 11-26.

Caves, R. (1998). Industrial organization and new findings on the turnover and mobility of firms. Journal of Economic Literature. 36(4). 1947-82.

Choy, H.L. (2012). Assessing earnings management flexibility. Review of Accounting and Finance. 11(4). 340-376.

Dickinson, V. (2011). Cash Flow Patterns as a Proxy for Firm Life Cycle. The Accounting Review. 86(6). 1969-1994.

Feenstra, D. W. \& Wang, H. (2000). Economic and accounting rates of return. Working Paper. University of Groningen. Research Institute SOM. SOM-theme E Financial markets and institutions. E42. Netherlands.

Gallizo, J. \& Salvador, M. (2003). Understanding the behaviour of financial ratios: the adjustment process. Journal of Economics and Business. 55. 267-83.

Ioannides, C., Peel, D. \& Peel, M. (2003). The time series properties of financial ratios: Lev revisited. Journal of Business Finance and Accounting. 30.699-714.

Jovanovic, B. (1982). Selection and the evolution of industry. Econometrica. 50(3).649-670.

Jovanovic, B. \& MacDonald, G. (1994). The life cycle of a competitive industry. Journal of Political Economy. 102(2). 322-347.

Kucharavy, D. \& De Guio, R. (2015). Application of logistic growth curve. Procedia Engineering 131. 280 - 290.

Laitinen, E.K. (2017). Profitability ratios in the early stages of a startup. The Journal of Entrepreneurial Finance. 19(2). 1-28.

Laitinen, E.K. (2018). Implied expense theory in financial reporting: a steady-state approach, Journal of Financial Reporting and Accounting. 16(1). 49-83.

Losbichler, H., Hofer, P., Eisl, C. \& Zauner, B. (2012). An Investigation of ROCE and Its Drivers: Empirical Analysis of European Companies. In Jodlbauer, H., Olhager, J. \& Schonberger, R.J. (Eds.). Modelling Value. Series:

Contributions to Management Science. Selected Papers of the 1st International Conference on Value Chain Management. Physica-Verlag GmbH Co. 119-148.

McLeay, S. \& Stevenson, M. (2009). Modelling the longitudinal properties of financial ratios. Applied Financial Economics. 19. 305-318.

Modis, 1994 Modis, Theodore (1994). Life Cycles - Forecasting the rise and fall of almost anything. The Futurist. 28(5): 20-25.

Modis, T. (1997). Genetic re-engineering of corporations. Technological Forecasting and Social Change. 56(2). 107-118. 
Modis, T. (2007). Strengths and weaknesses of S-curves. Technological Forecasting \& Social Change. 74. 866-872.

Murphy, G., Trailer, J., \& Hill, R. (1996). Measuring performance in entrepreneurship research. Journal of Business Research. 36(1). 15-23.

Oster, S. (1990). Modern Competitive Analysis. New York, NY: Oxford University Press.

Penman, S. \& Zhang, X. (2006). Modeling Sustainable Earnings and P/E Ratios with Financial Statement Analysis. Working paper, Columbia University and University of California, Berkeley.

Selling, T. \& Stickney, C. (1989). The effects of business environment and strategy on a firm's rate of return on assets. Financial Analysts Journal. 45(1). 43-52.

Shy, O. (1995). Industrial Organization: Theory and Application. Cambridge, MA: The MIT Press.

Spence, M. (1977). Entry, capacity, investment, and oligopolistic pricing. Bell Journal of Economics. 8(2). 534-544.

Spence, M. (1979). Investment strategy and growth in a new market. Bell Journal of Economics. 10(1). 1-19.

Spence, M. (1981). The learning curve and competition. Bell Journal of Economics. 12(1). 49-70.

Wernerfelt, B. (1985). The dynamics of prices and market shares over the product life cycle. Management Science. 31(8). 928-939.

Whittington, G. \& Tippett, M. (1999). The components of accounting ratios as co-integrated variables. Journal of Business Finance \& Accounting. 26(9-10). 1245-1273. 


\section{APPENDICES}

Appendix 1. Numerical values of the model variables in the base case $(C=1-q=0.65)$.

\begin{tabular}{|c|c|c|c|c|c|c|c|c|c|}
\hline Period $t$ & $E_{t}$ & $R_{t}$ & $D_{t}$ & $A_{t}$ & $\mathrm{PRM}_{\mathrm{t}}$ & $\mathrm{ROI}_{\mathrm{t}}$ & $\mathrm{CFM}_{\mathrm{t}}$ & $g_{t}^{E}$ & $g_{t}^{A}$ \\
\hline 0 & 85,00 & 57,95 & 55,25 & 29,75 & 4,67 & & $-46,67$ & & \\
\hline 1 & 88,95 & 80,93 & 77,16 & 41,55 & 4,67 & 12,70 & $-9,91$ & 4,65 & 39,65 \\
\hline 2 & 93,08 & 91,79 & 87,50 & 47,12 & 4,67 & 10,31 & $-1,40$ & 4,64 & 13,41 \\
\hline 3 & 97,39 & 98,53 & 93,93 & 50,58 & 4,67 & 9,76 & 1,16 & 4,63 & 7,34 \\
\hline 4 & 101,89 & 103,95 & 99,10 & 53,36 & 4,67 & 9,59 & 1,99 & 4,62 & 5,51 \\
\hline 5 & 106,59 & 109,06 & 103,97 & 55,98 & 4,67 & 9,54 & 2,26 & 4,61 & 4,91 \\
\hline 6 & 111,50 & 114,19 & 108,86 & 58,62 & 4,67 & 9,52 & 2,36 & 4,61 & 4,71 \\
\hline 7 & 116,62 & 119,48 & 113,91 & 61,33 & 4,67 & 9,51 & 2,39 & 4,60 & 4,63 \\
\hline 8 & 121,97 & 124,98 & 119,15 & 64,16 & 4,67 & 9,51 & 2,41 & 4,59 & 4,60 \\
\hline 9 & 127,56 & 130,71 & 124,61 & 67,10 & 4,67 & 9,51 & 2,42 & 4,58 & 4,59 \\
\hline 10 & 133,38 & 136,69 & 130,31 & 70,17 & 4,67 & 9,51 & 2,42 & 4,57 & 4,57 \\
\hline 11 & 139,46 & 142,93 & 136,26 & 73,37 & 4,67 & 9,51 & 2,43 & 4,56 & 4,56 \\
\hline 12 & 145,80 & 149,44 & 142,46 & 76,71 & 4,67 & 9,50 & 2,43 & 4,55 & 4,55 \\
\hline 13 & 152,42 & 156,22 & 148,93 & 80,19 & 4,67 & 9,50 & 2,44 & 4,54 & 4,54 \\
\hline 14 & 159,32 & 163,30 & 155,68 & 83,83 & 4,67 & 9,50 & 2,44 & 4,53 & 4,53 \\
\hline 15 & 166,51 & 170,68 & 162,72 & 87,62 & 4,67 & 9,50 & 2,45 & 4,51 & 4,52 \\
\hline 16 & 174,01 & 178,38 & 170,05 & 91,57 & 4,67 & 9,50 & 2,45 & 4,50 & 4,51 \\
\hline 17 & 181,82 & 186,40 & 177,70 & 95,69 & 4,67 & 9,50 & 2,46 & 4,49 & 4,50 \\
\hline 18 & 189,96 & 194,76 & 185,67 & 99,98 & 4,67 & 9,50 & 2,46 & 4,48 & 4,48 \\
\hline 19 & 198,45 & 203,47 & 193,98 & 104,45 & 4,67 & 9,50 & 2,47 & 4,47 & 4,47 \\
\hline 20 & 207,28 & 212,55 & 202,63 & 109,11 & 4,67 & 9,50 & 2,48 & 4,45 & 4,46 \\
\hline 21 & 216,49 & 222,00 & 211,64 & 113,96 & 4,67 & 9,50 & 2,48 & 4,44 & 4,45 \\
\hline 22 & 226,07 & 231,84 & 221,02 & 119,01 & 4,67 & 9,49 & 2,49 & 4,43 & 4,43 \\
\hline 23 & 236,04 & 242,08 & 230,79 & 124,27 & 4,67 & 9,49 & 2,49 & 4,41 & 4,42 \\
\hline 24 & 246,42 & 252,75 & 240,95 & 129,74 & 4,67 & 9,49 & 2,50 & 4,40 & 4,40 \\
\hline 25 & 257,22 & 263,84 & 251,53 & 135,44 & 4,67 & 9,49 & 2,51 & 4,38 & 4,39 \\
\hline 26 & 268,46 & 275,38 & 262,53 & 141,36 & 4,67 & 9,49 & 2,52 & 4,37 & 4,37 \\
\hline 27 & 280,14 & 287,39 & 273,98 & 147,53 & 4,67 & 9,49 & 2,52 & 4,35 & 4,36 \\
\hline 28 & 292,28 & 299,87 & 285,87 & 153,93 & 4,67 & 9,49 & 2,53 & 4,33 & 4,34 \\
\hline 29 & 304,90 & 312,84 & 298,24 & 160,59 & 4,67 & 9,48 & 2,54 & 4,32 & 4,33 \\
\hline 30 & 318,01 & 326,32 & 311,09 & 167,51 & 4,67 & 9,48 & 2,55 & 4,30 & 4,31 \\
\hline 31 & 331,63 & 340,32 & 324,44 & 174,70 & 4,67 & 9,48 & 2,55 & 4,28 & 4,29 \\
\hline 32 & 345,77 & 354,86 & 338,30 & 182,16 & 4,67 & 9,48 & 2,56 & 4,26 & 4,27 \\
\hline 33 & 360,44 & 369,96 & 352,69 & 189,91 & 4,67 & 9,48 & 2,57 & 4,24 & 4,25 \\
\hline 34 & 375,66 & 385,62 & 367,62 & 197,95 & 4,67 & 9,48 & 2,58 & 4,22 & 4,23 \\
\hline 35 & 391,45 & 401,87 & 383,11 & 206,29 & 4,67 & 9,47 & 2,59 & 4,20 & 4,21 \\
\hline 36 & 407,82 & 418,71 & 399,17 & 214,94 & 4,67 & 9,47 & 2,60 & 4,18 & 4,19 \\
\hline 37 & 424,79 & 436,18 & 415,82 & 223,90 & 4,67 & 9,47 & 2,61 & 4,16 & 4,17 \\
\hline 38 & 442,36 & 454,27 & 433,07 & 233,19 & 4,67 & 9,47 & 2,62 & 4,14 & 4,15 \\
\hline 39 & 460,55 & 473,01 & 450,93 & 242,81 & 4,67 & 9,47 & 2,63 & 4,11 & 4,12 \\
\hline 40 & 479,38 & 492,40 & 469,43 & 252,77 & 4,67 & 9,46 & 2,64 & 4,09 & 4,10 \\
\hline 41 & 498,86 & 512,47 & 488,56 & 263,07 & 4,67 & 9,46 & 2,66 & 4,06 & 4,08 \\
\hline 42 & 518,99 & 533,23 & 508,34 & 273,72 & 4,67 & 9,46 & 2,67 & 4,04 & 4,05 \\
\hline
\end{tabular}


Laitinen, E. K., \& Laitinen, T. (2018). Financial reporting: profitability ratios in the different stages of life cycle. Archives of Business Research, 6(11), 95-115.

\begin{tabular}{|c|c|c|c|c|c|c|c|c|c|}
\hline 43 & 539,80 & 554,68 & 528,79 & 284,73 & 4,67 & 9,46 & 2,68 & 4,01 & 4,02 \\
\hline 44 & 561,29 & 576,83 & 549,91 & 296,11 & 4,67 & 9,45 & 2,69 & 3,98 & 3,99 \\
\hline 45 & 583,46 & 599,71 & 571,72 & 307,85 & 4,67 & 9,45 & 2,71 & 3,95 & 3,97 \\
\hline 46 & 606,34 & 623,31 & 594,22 & 319,97 & 4,67 & 9,45 & 2,72 & 3,92 & 3,94 \\
\hline 47 & 629,91 & 647,64 & 617,42 & 332,46 & 4,67 & 9,45 & 2,74 & 3,89 & 3,90 \\
\hline 48 & 654,19 & 672,72 & 641,32 & 345,33 & 4,67 & 9,44 & 2,75 & 3,85 & 3,87 \\
\hline 49 & 679,18 & 698,53 & 665,93 & 358,58 & 4,67 & 9,44 & 2,77 & 3,82 & 3,84 \\
\hline 50 & 704,88 & 725,09 & 691,25 & 372,21 & 4,67 & 9,44 & 2,79 & 3,78 & 3,80 \\
\hline 51 & 731,29 & 752,39 & 717,28 & 386,23 & 4,67 & 9,43 & 2,80 & 3,75 & 3,77 \\
\hline 52 & 758,40 & 780,43 & 744,01 & 400,62 & 4,67 & 9,43 & 2,82 & 3,71 & 3,73 \\
\hline 53 & 786,20 & 809,20 & 771,43 & 415,39 & 4,67 & 9,43 & 2,84 & 3,67 & 3,69 \\
\hline 54 & 814,69 & 838,69 & 799,55 & 430,53 & 4,67 & 9,42 & 2,86 & 3,62 & 3,64 \\
\hline 55 & 843,84 & 868,88 & 828,34 & 446,03 & 4,67 & 9,42 & 2,88 & 3,58 & 3,60 \\
\hline 56 & 873,64 & 899,77 & 857,78 & 461,88 & 4,67 & 9,41 & 2,90 & 3,53 & 3,55 \\
\hline 57 & 904,06 & 931,32 & 887,86 & 478,08 & 4,67 & 9,41 & 2,93 & 3,48 & 3,51 \\
\hline 58 & 935,07 & 963,51 & 918,54 & 494,60 & 4,67 & 9,41 & 2,95 & 3,43 & 3,46 \\
\hline 59 & 966,64 & 996,30 & 949,80 & 511,43 & 4,67 & 9,40 & 2,98 & 3,38 & 3,40 \\
\hline 60 & 998,72 & 1029,65 & 981,60 & 528,55 & 4,67 & 9,40 & 3,00 & 3,32 & 3,35 \\
\hline 61 & 1031,27 & 1063,52 & 1013,89 & 545,94 & 4,67 & 9,39 & 3,03 & 3,26 & 3,29 \\
\hline 62 & 1064,24 & 1097,85 & 1046,62 & 563,56 & 4,67 & 9,38 & 3,06 & 3,20 & 3,23 \\
\hline 63 & 1097,55 & 1132,57 & 1079,72 & 581,39 & 4,67 & 9,38 & 3,09 & 3,13 & 3,16 \\
\hline 64 & 1131,13 & 1167,62 & 1113,14 & 599,38 & 4,67 & 9,37 & 3,13 & 3,06 & 3,09 \\
\hline 65 & 1164,90 & 1202,92 & 1146,78 & 617,50 & 4,67 & 9,37 & 3,16 & 2,99 & 3,02 \\
\hline 66 & 1198,76 & 1238,36 & 1180,57 & 635,69 & 4,67 & 9,36 & 3,20 & 2,91 & 2,95 \\
\hline 67 & 1232,61 & 1273,84 & 1214,39 & 653,90 & 4,67 & 9,35 & 3,24 & 2,82 & 2,87 \\
\hline 68 & 1266,33 & 1309,25 & 1248,15 & 672,08 & 4,67 & 9,34 & 3,28 & 2,74 & 2,78 \\
\hline 69 & 1299,77 & 1344,45 & 1281,70 & 690,15 & 4,67 & 9,34 & 3,32 & 2,64 & 2,69 \\
\hline 70 & 1332,80 & 1379,28 & 1314,92 & 708,03 & 4,67 & 9,33 & 3,37 & 2,54 & 2,59 \\
\hline 71 & 1365,24 & 1413,60 & 1347,63 & 725,65 & 4,67 & 9,32 & 3,42 & 2,43 & 2,49 \\
\hline 72 & 1396,92 & 1447,20 & 1379,67 & 742,90 & 4,67 & 9,31 & 3,47 & 2,32 & 2,38 \\
\hline 73 & 1427,61 & 1479,89 & 1410,83 & 759,68 & 4,67 & 9,30 & 3,53 & 2,20 & 2,26 \\
\hline 74 & 1457,10 & 1511,44 & 1440,90 & 775,87 & 4,67 & 9,28 & 3,60 & 2,07 & 2,13 \\
\hline 75 & 1485,13 & 1541,59 & 1469,65 & 791,35 & 4,67 & 9,27 & 3,66 & 1,92 & 1,99 \\
\hline 76 & 1511,42 & 1570,07 & 1496,80 & 805,97 & 4,67 & 9,26 & 3,74 & 1,77 & 1,85 \\
\hline 77 & 1535,67 & 1596,57 & 1522,07 & 819,58 & 4,67 & 9,24 & 3,81 & 1,60 & 1,69 \\
\hline 78 & 1557,54 & 1620,76 & 1545,13 & 831,99 & 4,67 & 9,23 & 3,90 & 1,42 & 1,52 \\
\hline 79 & 1576,66 & 1642,27 & 1565,63 & 843,03 & 4,67 & 9,21 & 3,99 & 1,23 & 1,33 \\
\hline 80 & 1592,63 & 1660,68 & 1583,18 & 852,48 & 4,67 & 9,19 & 4,10 & 1,01 & 1,12 \\
\hline 81 & 1604,99 & 1675,55 & 1597,36 & 860,11 & 4,67 & 9,17 & 4,21 & 0,78 & 0,90 \\
\hline 82 & 1613,26 & 1686,39 & 1607,69 & 865,68 & 4,67 & 9,15 & 4,34 & 0,52 & 0,65 \\
\hline 83 & 1616,90 & 1692,67 & 1613,68 & 868,91 & 4,67 & 9,12 & 4,48 & 0,23 & 0,37 \\
\hline 84 & 1615,34 & 1693,80 & 1614,76 & 869,49 & 4,67 & 9,10 & 4,63 & $-0,10$ & 0,07 \\
\hline 85 & 1607,93 & 1689,15 & 1610,32 & 867,10 & 4,67 & 9,07 & 4,81 & $-0,46$ & $-0,27$ \\
\hline 86 & 1593,98 & 1678,00 & 1599,70 & 861,38 & 4,67 & 9,03 & 5,01 & $-0,87$ & $-0,66$ \\
\hline 87 & 1572,72 & 1659,61 & 1582,16 & 851,93 & 4,67 & 8,99 & 5,24 & $-1,33$ & $-1,10$ \\
\hline
\end{tabular}




\begin{tabular}{|c|c|c|c|c|c|c|c|c|c|}
88 & 1543,34 & 1633,14 & 1556,93 & 838,34 & 4,67 & 8,95 & 5,50 & $-1,87$ & $-1,60$ \\
\hline 89 & 1504,92 & 1597,68 & 1523,12 & 820,14 & 4,67 & 8,89 & 5,81 & $-2,49$ & $-2,17$ \\
\hline 90 & 1456,49 & 1552,25 & 1479,81 & 796,82 & 4,67 & 8,83 & 6,17 & $-3,22$ & $-2,84$ \\
\hline 91 & 1396,99 & 1495,78 & 1425,97 & 767,83 & 4,67 & 8,76 & 6,60 & $-4,09$ & $-3,64$ \\
\hline 92 & 1325,24 & 1427,10 & 1360,50 & 732,58 & 4,67 & 8,67 & 7,14 & $-5,14$ & $-4,59$ \\
\hline 93 & 1240,00 & 1344,94 & 1282,17 & 690,40 & 4,67 & 8,57 & 7,80 & $-6,43$ & $-5,76$ \\
\hline 94 & 1139,89 & 1247,92 & 1189,69 & 640,60 & 4,67 & 8,44 & 8,66 & $-8,07$ & $-7,21$ \\
\hline 95 & 1023,42 & 1134,56 & 1081,61 & 582,41 & 4,67 & 8,27 & 9,80 & $-10,22$ & $-9,08$ \\
\hline 96 & 888,99 & 1003,23 & 956,41 & 514,99 & 4,67 & 8,04 & 11,39 & $-13,14$ & $-11,58$ \\
\hline 97 & 734,85 & 852,16 & 812,39 & 437,44 & 4,67 & 7,72 & 13,77 & $-17,34$ & $-15,06$ \\
\hline 98 & 559,10 & 679,46 & 647,75 & 348,79 & 4,67 & 7,25 & 17,71 & $-23,92$ & $-20,27$ \\
\hline 99 & 359,68 & 483,05 & 460,51 & 247,96 & 4,67 & 6,46 & 25,54 & $-35,67$ & $-28,91$ \\
\hline 100 & 134,38 & 260,69 & 248,52 & 133,82 & 4,67 & 4,91 & 48,45 & $-62,64$ & $-46,03$ \\
\hline
\end{tabular}

